\title{
LA INFLUENCIA DE LA NUEVA TELEVISIÓN EN LAS EMOCIONES Y EN LA EDUCACIÓN DE LOS NIÑOS
}

\author{
Dr. Serafín Aldea Muñoz ${ }^{1}$
}

\begin{abstract}
RESUMEN
Este trabajo de investigación lo he realizado teniendo en cuenta la proliferación de los programas denominados “ tele-basura “, que están obteniendo audiencias millonarias inimaginables y generando grandes intereses económicos.

Sin embargo, es indudable que la Televisión y estos programas tienen su incidencia sobre la educación, la socialización y la formación de actitudes en los niños teniendo en cuenta que ven un promedio de 25 horas semanales de televisión y que son excelentes imitadores.

A través de la aplicación empírica encuestional directa, me propongo comprobar unas hipótesis de investigación.

Sin embargo, solamente he incluido los resultados de los niños de educación infantil comprendidos entre 3 y 6 años, aunque también poseo los datos de los niños entre 7 y 12 años, que están a su disposición. No los he incluido porque el artículo superaría, con creces, la extensión máxima estimada por la Revista para poder publicarlo.
\end{abstract}

\section{PALABRAS CLAVE}

Telerrealidad, telebasura, imitación, actitudes, educación, valores

\footnotetext{
${ }^{1}$ Director Departamento de psicología Universidad de Soria. Correo electrónico: aldea@psi.uva.es
} 


\section{SUMMARY}

This research project has been carried out keeping in mind the proliferation of the socalled "tele-rubbish" programmes on television which attract millions of spectators and generate huge economic interest. Nevertheless, there can be no doubt that these programmes have a considerable influence on the education, socialization and development of attitudes in children, given that these watch an average of 25 hours of television per week and are also excellent imitators.

Through a direct empirical questionnaire, my proposal is to demonstrate this hypothesis. However, I have only included the most significant results for children in infant education between 3 and 6 years of age, although I also have data for children between 7 and 17 years in my possession and available to any interested parties. These data have not been included as this article would then become far too extensive for the limits established for publication in the magazine.

\section{KEY WORDS}

Telereality, tele-rubbish, imitation, attitudes, education, values.

\section{INTRODUCCIÓN}

El principal motivo por el que he realizado este trabajo de investigación ha sido porque considero importante saber la incidencia de la nueva programación (Gran Hermano, Operación Triunfo, Salsa Rosa, Crónicas Marcianas, Hotel Glamour...), que está avasallando nuestras pantallas en los últimos tiempos.

Últimamente hemos visto que la televisión ha ido degradando su imagen en gran medida, haciendo desaparecer los pocos programas culturales existentes o restándole importancia a asuntos de mayor importancia.

Se ha señalado y con razón que si el siglo pasado se caracterizó por la revolución industrial, el siglo XX ofreció como mayor característica la revolución en el terreno de las comunicaciones. Los datos más recientes revelan que cada ciudadano español ve la 
televisión 208 minutos al día, es decir, una media de 3 horas y media cada jornada (52 días enteros al año). En los últimos tiempos han surgido con audiencias millonarias los llamados "reality shows" o programas de telerrealidad como "Gran Hermano", "El Bus", "Supervivientes", “Operación Triunfo", "Confianza Ciega", etc. Algunos de estos espacios se han impuesto, en términos de audiencia, sobre otras opciones televisivas tradicionales como las películas, las series de ficción o los espacios infantiles, y se han convertido en los programas más vistos con seguimientos millonarios (las dos ediciones anteriores de Gran Hermano finalizaron con más de 9 millones de espectadores cada una, y Operación Triunfo lleva camino de batir todos los registros).

Con las cifras de la audiencia como testigo, muchas cadenas buscan el "cotilleo" y han acabado imponiendo un nuevo orden en el universo rosa, con reglas más “ sucias" y una nómina de personajes que son pura picaresca, actores de usar y tirar en programas hechos a su medida que mucha gente considera " basura " pero que otra mucha consume en raciones diarias.

No hay más que hacer zapping, a cualquier franja horaria, para que uno se empache con un contundente menú de piques, revolcones, rupturas, denuncias, querellas, insultos y demás exquisiteces. Todo ello, salpicado por los comentarios de un grupo de tertulianos desbocados, y servido entre tandas de anuncios, aplausos y abucheos del publico.

Las cadenas de televisión siguen apostando fuerte por estos contenidos, pero como la tele quema todo lo que toca, han tenido que inventar nuevos formatos, un circo con nuevos números que pasa por el uso de la cámara oculta de los concursos y de los “ cutrefamosos "bajo el ojo de las camaras.

Pero la comunicación de la información universal a través de los medios contemporáneos exige una fundamentación ética por parte de los que la dirigen y una colocación de los medios al servicio de la educación sana, de la verdad, de la socialización constructiva y de la armonía recíproca entre los hombres. Esto es especialmente importante en cuanto se refiere a la información suministrada a los niños, los cuales constituyen la mayor audiencia, dispuesta a ser amenizada, distraída y alimentada mentalmente.

A pesar de la constante y creciente introducción (o mejor dicho, intrusión) de la televisión, en la mayoría de los hogares, se observa una negligencia o despreocupación por la influencia que ejerce sobre las mentes en desarrollo y aun sobre la estructura de la familia, que día a día y lentamente es avasallada por el crimen y la banalidad, por el culto a la estupidez y lo superfluo, que están sustituyendo los valores más nobles y positivos de la vida.

Una o como mucho dos horas al día delante de la tele, ese es el tiempo máximo que aconseja la Academia Americana de Pediatría para los niños en edad escolar. En nuestro país, según Sofres, la empresa que estima las audiencias televisivas, la media de permanencia diaria frente al televisor de los españoles mayores de cuatro años es de 220 minutos, o lo que es lo mismo, 3 horas y 40 minutos. Esto significa que muchos niños pasan delante de la tele bastante más tiempo de lo que realmente es saludable para ellos. La explicación es simple; les encanta. Dibujos animados, series, concursos, programas musicales, anuncios publicitarios, deportes... La mayoría conoce la programación mucho mejor que sus propios padres. Y realmente, frente a la crisis de valores que 
atraviesa nuestra programación, hay pocos programas destacables que tal vez con un estilo sano transmitan cultura y entretenimiento divertido.( Marco.2003 )

Teniendo en cuenta la importancia de todos los datos mencionados anteriormente, lo que más me preocupa es que esta nueva programación televisiva no solo influye en los adultos sino también en los niños.

Por estas razones, creo que es importante la necesidad de analizar lo que la gente opina al respecto y ver cuales son los efectos que realmente produce la televisión en nuestra sociedad.

\section{LA TELEREALIDAD}

Los datos más recientes afirman que cada ciudadano español ve la televisión un total de 3 horas y 40 minutos cada día, lo cual es totalmente desmesurado. Con la llegada de los nuevos valores sociales, se están implantando en nuestros televisores los llamados "reality shows" o programas de telerrealidad, que se han impuesto contundentemente sobre otras opciones televisivas como pueden ser las películas, las series o los documentales. Estos nuevos programas de telerrealidad (como son "Gran Hermano", "Operación Triunfo", "El Bus", "Confianza Ciega", "Pop Stars"...) están obteniendo audiencias millonarias inimaginables, están batiendo récords. ( Olza.2003).

Teniendo en cuenta los grandes índices de audiencia de los diversos programas que se están poniendo de actualidad en los últimos tiempos, la llamada "tele basura", no es de extrañar que llegados a este punto nos encontremos en medio de un interesante debate sobre la calidad de estos programas. Hay desde quien los encuadra en la sección de lo absolutamente deleznable hasta quien cree que se está gestando un nuevo concepto de democracia digital, sin olvidar los intelectuales y pensadores, que han comenzado ya a interesarse por el impresionante efecto social conseguido por alguno de estos espacios.

En este sentido el filósofo Gustavo Bueno defiende a la televisión y a los espacios de telerrealidad cuando reflejan sin interferencias aspectos de la vida cotidiana de las personas, los entiende como "estudios sociológicos", y defiende a "Gran Hermano" porque es más fiel a la realidad de la sociedad de la que surge y porque permite a los espectadores apreciar en los concursantes valores como la amistad, la generosidad o contravalores como la envidia o el machismo. Sin embargo, en contraposición de estas ideas, se encuentra el Catedrático de la Universidad Autónoma de Barcelona, Román Guber, que opina que "Gran Hermano es un pacto interesado (por los premios y la popularidad) entre el exhibicionismo rentabilizable de unos cuantos y la voracidad mirona del publico, que convierte las pantallas domesticas en agujeros de cerraduras". Guber atribuye esta situación al gobierno implacable del sistema televisivo por parte de un espiral sensacionalista que, en función de la progresiva permisividad social, anuncia un porvenir poco o nada edificante.( Silva. 2002 ) 
Detrás de estos espacios, como puede suponerse, existen también grandes intereses económicos. Y no solo de las propias cadenas de televisión, que juegan millones de euros en cada apuesta televisiva en plena recesión de la inversión publicitaria. También hay que destacar el impresionante crecimiento de los ingresos de las compañías telefónicas como consecuencia de los mensajes enviados a los concursos de TV. Se ha calculado que en los días finales de la ultima edición de "Gran Hermano" se enviaron más de un millón de mensajes. Cifras que ampliamente fueron superadas por "Operación Triunfo" en este año que, en momentos de máxima audiencia, consiguió superar los 1000 mensajes por minuto. De hecho, en los últimos meses, se han creado más de 40 empresas especializadas en servicios interactivos (concursos, sorteos, chats, etc.). Por estos conceptos, el pasado año se facturaron 120 millones de euros (20.000 millones de las antiguas pesetas) y este año se espera triplicar la cifra en función de los más de 10.000 millones de mensajes cortos enviados desde los 30 millones de móviles existentes en España. De cada mensaje corto (SMS) enviado a un concurso televisivo (cuyo precio oscila entre los 0,3 y 0,9 euros sin IVA), la operadora del móvil se lleva aproximadamente la mitad y el resto se lo reparten el proveedor del servicio y el programa que organiza el concurso. Y todo ello, sin olvidar la repercusión que tendrá en el mercado musical el fenómeno "Operación Triunfo", ya que varios de sus concursantes han vencido ya decenas de miles de copias de sus discos y su caché por actuación, cercanos a los 60.000 euros en el caso de Rosa López (ganadora de la primera edición), se sitúa a la altura de los cantantes más consolidados, para sorpresa de éstos y preocupación de sus compañías de discos, que temen un autentico terremoto de consecuencias imprevisibles en la industria musical.( Silva. 2002 )

Está claro que el fenómeno acaba de asomar y que los programas de telerrealidad van a ocupar los espacios centrales de la programación de las cadenas de televisión en los próximos tiempos. Tele 5 dio la campanada con "Gran Hermano" en la primavera del año 2000 y TVE contraatacó de manera espectacular con "Operación Triunfo", pero esto solo fue el principio ya que les fueron siguiendo otros muchos (de los cuales algunos han fracasado); "Confianza Ciega", "Supervivientes", "El Bus", "Pop Stars", etc.

La interactividad de estos concursos, la posibilidad de votar para premiar o castigar a los concursantes, se revela como el factor más novedoso para el espectador en la medida que le otorga el papel de dueño del futuro de los diferentes protagonistas.

Descalificar un programa de televisión únicamente porque sea seguido por millones de personas no parece ser un argumento muy consistente teniendo en cuenta que las sociedades modernas se diferencian de las demás, precisamente, por estar gobernadas según los criterios de la mayoría. Aunque eso no significa que la mayoría siempre tenga que tener razón... 


\section{EL NIÑO Y LA TELEVISIÓN}

Es evidente, que la TV es una fuente efectiva para la creación y formación de actitudes en los niños, ya que desde temprana edad, son sometidos a su influencia sin poseer otro tipo de información.

Según la teoría de socialización comunitaria de Erickson, es entre los 2 y 6 años cuando se perfilan los sentimientos preferenciales hacia la madre, padre, familiares y otras personas significativas; A través de este proceso el niño adquiere habilidades y formas de comportarse en la sociedad. Es a partir de los 4 a 5 años de edad, que se establecen los hábitos permanentes y las características emocionales, jugando un papel decisivo la imitación y la identificación. Con esto, se refiere a pautas de conducta y actitudes de las personas que los rodean, esto llega a ocurrir incluso de manera inconsciente.

Los niños recurren a la televisión para satisfacer sus necesidades de distracción, reducir las tensiones y como medio para obtener información. Además de las motivaciones personales, podríamos agregar un factor situacional externo al niño; la ve porque se la impone el medio, no le queda otro remedio. Le es ofrecida en el ambiente del hogar y se le refuerza la conducta de contemplación por los padres. En muchos casos es la única compañía del niño y a veces se convierte en una especie de niñera.

Ver la televisión es incluso la actividad líder del niño, gastan más tiempo viendo la TV que haciendo cualquier otra actividad que no sea dormir. En promedios, los niños ven de 22 a 25 horas semanales de televisión. En general, se puede decir que durante el transcurso del año, los niños pasan más tiempo frente al televisor, que en la escuela. Es la TV, más que cualquier otro medio, la que proporciona una base común de información en las primeras fases de socialización del niño.(Villacastín.2002 ).

Los niños son excelentes imitadores, incluso durante los primeros meses de vida.Aprenden a comer, vestirse, utilizar el sanitario e interactúan con los demás. Ellos no son especialmente selectivos en lo que imitan, por lo que a muchos padres se les recomienda que cuiden su vocabulario cuando sus pequeños dicen una mala palabra en un momento de frustración. Aunque la imitación no es el único mecanismo de aprendizaje que tienen los niños, es el primero y sienta las bases de aprendizaje futuro. Como los niños imitan permanentemente a la gente que los rodea, es lógico que también imiten a las personas que ven en la televisión o en el cine.

Esto no es un problema que afecte solo a los niños, sino que a menudo también influye en los adolescentes. A lo largo de la vida imitamos a los demás para aprender cosas nuevas y reforzar nuestra identidad con un grupo particular. Con cierta frecuencia se oyen historias acerca de niños que terminan trágicamente, al imitar algún personaje que han visto en los medios de comunicación. Por ejemplo: un niño de cinco años que le prendió fuego a su casa y causó la muerte de su hermana de dos años, después de haber 
visto un episodio de dos pre-adolescentes estúpidos que disfrutan realizando actividades antisociales; un grupo de adolescentes que causó un accidente al imitar la escena de una película en la que varios jóvenes demuestran su valor acostándose sobre una autopista; un niño de trece años que se disparó en la cabeza mientras estaba jugando a la ruleta rusa que había visto en una película.

Todas estas historias son trágicas pero afortunadamente no se presentan muy a menudo.

La mayor parte de los niños no imitan tan fácilmente, solamente escogen algunas imágenes, actitudes y valores. Cuando se sienten frustrados, algunos niños lloran en un rincón, otros dan patadas y golpes, y otros toman con calma su frustración.

Si tenemos en cuenta la composición de los programas, debemos aceptar que la actual enseñanza incipiente se refiere a las formas del crimen y a la ilegalidad, a la corrupción destructiva, a la exagerada valoración de los bienes materiales con relación a los valores intelectuales y culturales.

Estudios de la Universidad de Stanford han demostrado que un niño medio de los EE.UU. ha presenciado, entre los 5 y los 14 años, veinte mil crímenes violentos que han alimentado su aparato mental. Otro estudio demostró que la TV ocupa el segundo lugar en el tiempo del niño, después de la escuela, tomando como promedio cuatro horas diarias de su atención en días laborables. Se ha investigado igualmente que la mayor parte de las series duran alrededor de una hora y durante la mayor parte de la trama, los criminales realizan sus fechorías con éxito, hasta que son castigados sólo en el momento final. Puesto que la mayor parte de los niños menores de 8 años no sostienen la atención más allá de media hora, aprenden en la película los procedimientos criminales sin que lleguen a aprender la moraleja final. Además, a esa edad el niño no distingue bien entre realidad y fantasía, entonces todas esas escenas pueden almacenarse en la memoria como si hubiesen sido hechos reales. El crimen y la violencia se tornan así en vivencias "normales" en la cotidianidad del niño.( Feinbloon,1989)

\section{EFECTOS NEGATIVOS DE LA TV EN LOS NIÑOS}

Hace ya bastantes años que los científicos demostraron que los contenidos televisivos afectan a los niños y favorecen que estos imiten o reproduzcan los modelos de conducta que ven. Por eso resulta tan grave la exposición sistemática a imágenes violentas; los críos aprenden a resolver sus problemas con violencia y se vuelven insensibles ante las consecuencias derivadas a sus acciones.

Los niños que ven durante más horas la televisión son más agresivos y pesimistas, menos imaginativos y empáticos, tienden a ser más obesos y no son tan buenos estudiantes. 
Está demostrado que el contenido de los mensajes de la televisión, sobre todo en el mundo accidental y más aun en los países subdesarrollados, es de baja calidad artística, con altos contenidos de violencia, agresión y exaltación de valores que no están de acuerdo con los intereses de nuestra sociedad. La exaltación del individualismo, el énfasis por el dinero y los bienes económicos, etc. La televisión ayuda a la formación de imágenes estereotipadas con respecto a profesionales, grupos étnicos, religiosos o políticos.

La TV presenta muchos más estereotipos de los que se encuentran en la vida real. Aparecen más hombres, y éstos son más agresivos, activos, constructivos y serviciales, sus actividades les aportan recompensas tangibles. Pero las mujeres tienden a ser diferentes, pasivas e ignoradas, y son castigadas si se vuelven muy activas. En los últimos años se está cambiado su imagen en la televisión, las mujeres pueden trabajar fuera de casa y, los hombres pueden estar a cargo de los niños, pero todavía hay muchos estereotipos del genero.

La teoría del aprendizaje social plantea que los niños imitan los modelos que ven y entonces, los que ven más TV estarían más tipificados por el género. Además, se demostró que ambos sexos recuerdan mejor las secuencias televisivas que confirman estereotipos, pero cuando éstos son rotos, los niños reaccionan, suelen ser más flexibles en sus visiones y aceptan que hombres y mujeres tengan ocupaciones no tradicionales. En las investigaciones se ha observado que las niñas son más receptivas a estos cambios, aceptan los roles no tradicionales tanto en los demás como en ellas mismas. (Drake.2003)

A pesar de los cambios en gran parte de televisión, se sigue retratando un mundo en el que se valora ser hombre, blanco y joven, y se denigra el ser mujer, viejo, de piel oscura o extranjero. A esto se le suma el que en los comerciales las diferencias entre los roles de género son mucho mayores en la vida real, y muy pocos de ellos rompen con los estereotipos.

Algo similar ocurre con las escenas de contenido erótico. Por un lado, casi nunca ofrecen educación sexual, es decir, nunca hablan por ejemplo de la posibilidad de contraer enfermedades. Por otro, dificultan que los niños puedan distinguir lo que es adecuado a su edad y lo que no, con lo que les puede resultar más difícil poner límites en un futuro.

Otro de los problemas asociados a la televisión es que, mientras los chavales están tumbados en el sofá, apenas mueven un músculo. Si encima se atiborran de chucherías delante de la pantalla, el camino hacia la temida obesidad está servido.

En algunos casos, la tele puede incluso crear adicción. Son niños que la enchufan nada más levantarse por la mañana o en cuanto llegan de la escuela. Dejan de hacer los deberes por una serie o por cualquier otra cosa, y cuando alguien apaga el aparato ponen 
el grito en el cielo o se muestran muy irritables. La vida que ven a través de la televisión les satisface más que su propia situación, y así eluden sus problemas de la peor forma.

Además de los aspectos negativos ya citados anteriormente, existen otros muchos que a menudo suelen pasar desapercibidos o no se les llega a dar tanta importancia. A continuación muestro una pequeña lista de algunos de ellos, como pueden ser:

Ø La televisión desplaza los tipos activos de recreación; Disminuye el tiempo dedicado a jugar con otros niños. Disponen de menos tiempo para usar su imaginación y para pensar. También la TV, les deja menos tiempo para los deportes, la música, el arte, etc.

Ø La televisión disminuye el tiempo disponible para la conversación y el intercambio de opiniones; Reduce las interacciones sociales con la familia y las amistades.

$\varnothing \quad$ La televisión reprime la inclinación a la lectura.

Ø Pasar demasiado tiempo viendo la televisión (más de 4 horas al día) decididamente disminuye el rendimiento escolar; El exceso de televisión interfiere en el estudio, la lectura y el tiempo para pensar. Si los niños no duermen lo suficiente porque están viendo la televisión, al día siguiente no estarán lo suficientemente atentos para poder aprender bien.

$\varnothing \quad$ La televisión reduce la voluntad para hacer ejercicios.

Ø La publicidad en la televisión fomenta la demanda de posesiones materiales; Los niños presionan a sus padres para que les compren los juguetes que ven anunciados. La televisión presenta el materialismo casi como un estilo de vida.(Marco.2003).

\section{EFECTOS POSITIVOS DE LA TELEVISIÓN EN LOS NIÑOS}

La televisión no solo tiene efectos negativos en la formación de los niños; sino que también es un invento fabuloso que nos permite, además de buenos ratos de entretenimiento, un conocimiento que, sin su existencia, sería imposible. No hay porque eliminarla o discriminarla por completo. Bien empleada, puede aportar a nuestros hijos muchas cosas buenas, ya que les permite conocer el mundo, aprender geografía y costumbres de otros pueblos, aficionarse a las manualidades, el bricolaje, la cocina...

Lo importante es estudiar la oferta y hacer mucho"zapping", teniendo en cuenta que, muchísimas veces, los valores con un valor educativo importante no están incluidos en la parrilla infantil, sino en el horario escolar. 
Les divierte ver programas como "Pasapalabra", un programa ideal para toda la familia; "El Conciertazo", un espacio donde enseñan música clásica de manera amena y divertida; "Waku Waku", en el que se puede aprender bastante de animales y ecología; ... Y seguramente se pueden mencionar otros muchos, solo hace falta buscar bien en las programaciones de las diferentes cadenas de televisión.

También hay películas que merecen la pena; y que fomentan la educación y la imaginación de los más pequeños de una manera sana. El problema es que la mayoría de ellas no se retransmiten a una hora adecuada; sino que las echan cuando los niños están en el colegio o de madrugada; ante estas situaciones, se pueden grabar y ser vistas luego por toda la familia.

Precisamente, ver la televisión con ellos y comentar los contenidos que aparecen en ella, es una regla de oro en el uso de la pequeña pantalla: Así sacan mejor provecho de los buenos programas, se contrarrestan los efectos nocivos de los que no lo son, se fomenta su espíritu crítico y, lo mejor, se llega a pasar un rato estupendo en familia. Por ello los padres pueden y deben ayudar a sus hijos a tener experiencias positivas con la televisión, de esta manera su deber es:

\section{$\varnothing \quad$ Mirar los programas con los hijos.}

$\varnothing \quad$ Escoger programas apropiados para el nivel de desarrollo del niño.

$\varnothing \quad$ Poner limites a la cantidad de tiempo que pasan ante la televisión (tanto a diario como por semana

$\emptyset \quad$ Apagar el televisor durante las horas de las comidas y del tiempo de estudio.

Ø Apagar los programas que no les parezcan apropiados para la edad de su hijo.

$\varnothing \quad$ No usar la televisión como distracción o como "niñera" en los niños de edad preescolar.

$\emptyset \quad$ Enseñarles a elegir los programas con discernimiento; enseñarles a consultar la guía de programación para elegir los programas más adecuados.

Ø Estimular a los hijos para ver programas educativos o que enseñen los valores humanos.

$\varnothing \quad$ Prohibir los programas violentos. 
$\emptyset \quad$ Discutir los anuncios publicitarios con sus hijos, ayudarles a identificar cuales exageran y cuales no.

Ø Hablar sobre la programación que ven, explicándoles las diferencias entre la realidad y la ficción.( Silva.2003).

\section{VIOLENCIA EN TV (Y SUS REPERCUSIONES EN LOS MÁS PEQUEÑOS)}

Nuestro medio social en la actualidad se presenta violento, si tenemos en cuenta que la televisión es parte de ese medio y que de él recibe los temas y a él lo devuelve en forma de influencia sobre los telespectadores.Podríamos decir que en parte la responsabilidad es el ambiente en donde se desenvuelve ese medio.

Gerbner y Gross, en un articulo titulado La Violencia Prolifera, demostraron que durante el año 1989 ocurrió violencia en el 73\% del total de programación de los Estados Unidos y en casi todas las caricaturas infantiles. Para ello usaron como medidas factores tales como: el porcentaje de programas de contenido violento, el numero de episodios violentos por programas y el porcentaje de personajes principales implicados en actos de violencia (Feinbloon.1989).

Actualmente, el tema de la violencia en televisión ha generado gran preocupación, debido a que estimula la conducta agresiva de los niños, los cuales pasan muchas horas frente al televisor viendo programas infantiles (tales como los Power Rangers o Dragon Ball Z), o para adultos, siendo los primeros mucho más agresivos. Entre los actos violentos que son vistos por los niños están; asesinatos, guerras, puñetazos, golpizas, cuchilladas, patadas, accidentes violentos y destrucción de propiedades, entre otros. Los niños que ven violencia en la pantalla se comportan más agresivos sin importar su localización geográfica, su sexo, su nivel económico o si tienen problemas emocionales. Este efecto es interdependiente, es decir, los niños agresivos eligen programas violentos y aquellos que ven estos programas, son más agresivos. La televisión fomenta la conducta agresiva de dos modos, o imitan el modelo que observaron y llegan a aceptar la agresión como conducta apropiada.

La imitación es el primer mecanismo de aprendizaje que tienen los niños y éstos no son especialmente selectivos en lo que imitan, y lo hacen tanto con modelos reales como con personas en la televisión o dibujos animados. Los niños no imitan tan fácilmente lo que ven, lo que aprenden en los medios es más que imitación, ya que, de la gran cantidad de conductas, imágenes, actitudes y valores a los cuales están expuestos, eligen solo algunos.

El niño, después de observar episodios violentos, puede que actúe violentamente pero esto no significa que no haya aprendido una solución agresiva. A medida que son 
mayores, la conducta agresiva refleja más estilo interpersonal que cada uno está desarrollando. Hay variables importantes en la eficacia de un mensaje de los medios de comunicación.

Cuando hablamos de violencia en TV debemos tener en cuenta dos aspectos importantes: por un lado, la "violencia real" como un reflejo del medio social que se difunde a través de noticieros y reportajes de noticias, y por otro, la "violencia ficticia o representada" que es la que con mayor frecuencia llega al público a través de casi toda la programación.( Olza.2003 ).

La "violencia real" afecta mayormente a la gente que la "violencia irreal". En un estudio se comprobó que los niños después de ver un episodio de violencia real eran más violentos que los que vieron un episodio ficticio. A diferentes edades, los niños consideran reales cosas muy diferentes, los niños pequeños consideran como "real" todo aquello que puede ocurrir, pero comprenden a muy temprana edad que los dibujos animados son menos reales, según algunos investigadores la violencia en la televisión produce menos efectos negativos si aparece en dibujos animados donde es castigada, las consecuencias negativas sean claras y el malhechor sea una persona completamente mala. Aunque los niños sepan que los dibujos animados no son reales, el ver frecuentes episodios de violencia en éstos igual aumenta la agresividad.

Los programas de televisión en los horarios de mayor audiencia muestran alrededor de cinco escenas violentas por hora, y los dibujos animados veintitrés por hora. Se ha descubierto que las personas que ven mucha televisión son más temerosas e inseguras, esto ocurre tanto en adultos como en niños. En general se nos presenta una idea equivoca y pesimista del mundo, lo cual afecta más a los niños ya que tienen menos fuentes de información.( Marco. 2003 )

Uno de los aspectos que más preocupa, sobre todo a los padres, es que los niños se estén volviendo insensibles ante la violencia, ya que ésta parece endurecer a los niños, quienes al ver un acto violento, tienden a reaccionar con indiferencia. Estudios han demostrado que ver con frecuencia episodios violentos disminuye reacciones emocionales y también el interés por ayudar a otras personas Cuanta más violencia veamos y cuanto menos perturbe, mas probabilidades tienemos de hacernos tolerantes a la violencia en la vida real. La desensibilizacion a la violencia se opone al sano desarrollo y es posible que esta reducción de la ansiedad sea lo que facilita el comportamiento agresivo. Por otra parte, investigadores han concluido que los niños que ven violencia en los medios de comunicación, tienen mas probabilidad de considerar las peleas como un mecanismo normal para solucionar los conflictos (Levine, 1997). 
Los psiquiatras de niños y adolescentes que han estudiado los efectos de la violencia, han encontrado que sus pacientes pueden tener una serie de comportamientos, como son:

\section{$\varnothing \quad$ Imitar la violencia que observan en televisión. \\ Ø Identificarse con ciertos tipos, caracteres, victimas y/o victimarios. \\ $\emptyset \quad$ Tornarse "inmunes" al horror de la violencia. \\ $\emptyset \quad$ Gradualmente aceptar la violencia como manera de resolver problemas.}

De manera que la exposición extensa a programas de televisión que contengan violencia causa mayor agresividad en los niños. En ocasiones, al ver tan solo un programa violento puede aumentar la agresividad. Los niños que ven espectáculos en los que la violencia es presentada de forma muy realista, repetida, o sin ser castigada, tiene mayor probabilidad de imitar lo que ven. El impacto de la violencia en la televisión puede reflejarse en la conducta del niño inmediatamente o manifestarse más tarde en su desarrollo. Los jóvenes pueden afectarse aún cuando en la atmósfera familiar no haya tendencia hacia la violencia. Esto no quiere decir que la violencia que se ve en televisión es la única causa de conducta violenta o agresiva, pero no hay duda de que es un factor significativo.

\section{METODOLOGÍA}

La metodología que se he empleado, de acuerdo con las características de la investigación, ha sido la empírica encuestional directa, es decir, realizando encuestas de manera personal y oral. Se ha encuestado a una muestra total de 120 niños, residentes en Aragón, Navarra, Castilla y León, Murcia y La Rioja; divididos por sexos y por grupos de edades, siendo estos:

\section{De 3 a 6 años.}

De 6 a 12 años

Solamente incluimos los datos, las tablas y las encuestas de los niños comprendidos entre 3 y 6 años debido a que el artículo tendría una gran extensión, pero ,por supuesto, 
disponemos de los datos por si algún investigador está interesado de las encuestas y gráficos más significativos de los niños entre 6 y 12 años

\section{HIPÓTESIS}

$\varnothing \quad$ Los niños ven masivamente este tipo de programas de televisión.

$\varnothing \quad$ Los niños se ven claramente influidos de manera negativa por este tipo de programación, sin embargo los adultos no son conscientes de ello.

$\varnothing \quad$ La televisión, como medio de comunicación que es, podría ser utilizado como un método bastante eficaz de aprendizaje, sobre todo en niños pequeños, si desapareciera la "programación basura".

$\varnothing \quad$ Los padres permiten que sus hijos vean cualquier tipo de programa, sin ningún tipo de control ni medida.

$\varnothing \quad$ Esta "nueva" televisión es uno de los temas de más actualidad que existen hoy en día a pie de calle.

\section{RESULTADOS Y ANALISIS ESTADISTICO DE LAS ENCUESTAS}

\section{Encuestas a niños y niñas de 3 a 6 años}

\section{1. ¿Te gusta ver la tele?}

\begin{tabular}{|c|c|c|}
\hline & NIN $\tilde{N} A S$ & NIÑNOS \\
\hline$S I$ & 91.4 & 92 \\
\hline $\mathrm{NO}$ & 8.5 & 8 \\
\hline
\end{tabular}




\section{2. ¿Ves mucho la televisión?}

\begin{tabular}{|c|c|c|}
\hline & $N I \tilde{N} A S$ & NIÑNOS \\
\hline$S I$ & 80 & 72 \\
\hline NO & 20 & 28 \\
\hline
\end{tabular}

\section{3. ¿Ves Operación Triunfo?}

\begin{tabular}{|c|c|c|}
\hline & NIÑNAS & NIÑNOS \\
\hline$S I$ & 82.8 & 60 \\
\hline Cantan bien & 48.5 & 28 \\
\hline Son guapos & 34.2 & 32 \\
\hline NO & 28.5 & 40 \\
\hline No dejan los padres & 20 & 16 \\
\hline No gusta & 8.5 & 24 \\
\hline
\end{tabular}

\section{4. ¿Ves Gran Hermano?}

\begin{tabular}{|c|c|c|}
\hline & NIN $\tilde{N} A S$ & NIÑNOS \\
\hline SI & 22.8 & 32 \\
\hline Lo ven padres & 5.7 & 12 \\
\hline Te gusta & 17.1 & 20 \\
\hline $\mathrm{NO}$ & 80 & 72 \\
\hline No dejan los padres & 54.2 & 40 \\
\hline No gusta & 25.7 & 32 \\
\hline
\end{tabular}


5. ¿Te gustaría ir a Operación Triunfo?

\begin{tabular}{|c|c|c|}
\hline & NIÑAS & NIÑ $\boldsymbol{O S}$ \\
\hline SI & 45.7 & 48 \\
\hline Te gusta cantar & 42.8 & 28 \\
\hline Quieres ser famoso & 2.8 & 20 \\
\hline NO & 54.2 & 52 \\
\hline
\end{tabular}

6. ¿Te gustaría ir a Gran Hermano?

\begin{tabular}{|c|c|c|}
\hline & NIÑAS & NIÑOS \\
\hline SI & 22.8 & 28 \\
\hline Quieres tener más amigos & 17.1 & 16 \\
\hline Quieres ser famoso & 5.7 & 12 \\
\hline & & \\
\hline NO & 77.14 & 80 \\
\hline
\end{tabular}

7. ¿Ves la televisión con tus padres?

\begin{tabular}{|c|c|c|}
\hline & $N I \tilde{N} A S$ & NIÑNOS \\
\hline$S I$ & 85.7 & 84 \\
\hline $\mathrm{NO}$ & 8.5 & 16 \\
\hline
\end{tabular}


8. ¿Te quedas viendo la televisión hasta muy tarde?

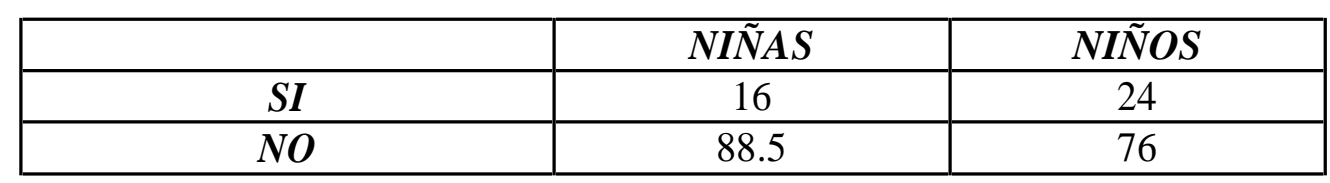

9. ¿Te dejan ver los programas que tú quieres?

\begin{tabular}{|c|c|c|}
\hline & NIÑNAS & NIÑNOS \\
\hline$S I$ & 20 & 40 \\
\hline$N O$ & 80 & 60 \\
\hline
\end{tabular}

10.Si tus padres no están, ¿qué programas ves?

\begin{tabular}{|c|c|c|}
\hline & NIN $\boldsymbol{A S}$ & NIN $\boldsymbol{O S}$ \\
\hline DIBUJOS & 22.8 & 32 \\
\hline PROGRAMAS & 2.8 & 4 \\
\hline SERIES & 8.5 & 12 \\
\hline NOTICIAS & 2.8 & 0 \\
\hline PELICULAS & 5.7 & 16 \\
\hline
\end{tabular}


11. ¿Qué dibujos te gustan ver?

\begin{tabular}{|c|c|c|}
\hline & NIÑAS & NIN $\boldsymbol{O S}$ \\
\hline POCKEMON & 11.4 & 0 \\
\hline LOS SIMPSON & 22.8 & 12 \\
\hline LOS RUGRAT & 5.7 & 12 \\
\hline LAS TRES MELLIZAS & 22.8 & 4 \\
\hline LOS TWINIS & 2.8 & 4 \\
\hline CLUB MEGATRIX & 2.8 & 8 \\
\hline TIMÓN $\boldsymbol{Y}$ PUMBA & 8.5 & 4 \\
\hline DIGIMON & 5.7 & 8 \\
\hline
\end{tabular}

12. En esos dibujos, ¿los protagonistas se pelean?

\begin{tabular}{|c|c|c|}
\hline & NIÑAS & NIÑOS \\
\hline SI & 51 & 52 \\
\hline NO & 48.5 & 48 \\
\hline
\end{tabular}

\section{3. ¿Por qué te gusta verlos?}

\begin{tabular}{|c|c|c|}
\hline & $N I \tilde{N} A S$ & NIÑNOS \\
\hline Solo hay esos dibujos & 37 & 30 \\
\hline Gustan como luchan & 25 & 36 \\
\hline Otras & 40 & 40 \\
\hline
\end{tabular}


14.

¿Qué otros programas, series, documentales te gustan ver?

\begin{tabular}{|c|c|c|}
\hline & NIÑNAS & NIÑNOS \\
\hline DIBUJOS & 5.7 & 16 \\
\hline DOCUMENTALES & 5.7 & 4 \\
\hline PELÍCULAS & 5.7 & 12 \\
\hline SERIES & 45.7 & 12 \\
\hline $\begin{array}{l}\text { PROGRAMAS } \\
\text { INFANTILES }\end{array}$ & 2.8 & 4 \\
\hline OTROS & 11.4 & 16 \\
\hline
\end{tabular}

\section{DISCUSION Y ANALISIS DE LOS DATOS DE LAS ENCUESTAS}

\section{A NIÑOS/AS DE 3 A 6 AÑNOS}

Después de realizar estas tablas estadísticas, el dato que más llama la atención es el porcentaje tan elevado de niñas y niños de entre 3 y 6 años que ven la televisión, siendo estos de un $80 \%$ y un $72 \%$ respectivamente, ya que para ellos es una forma divertida de pasar el rato y les gusta entretenerse de esta manera. (Pregunta 2)

Tal y como se puede comprobar, el programa Operación Triunfo tiene gran aceptación entre los niños de estas edades, sobre todo en el sector femenino, obteniendo los siguientes resultados; el porcentaje de niñas que ven dicho programa es de un $82.8 \%$ (de las cuales un $48.5 \%$ lo ven porque los participantes cantan bien y un $34.2 \%$ simplemente lo ven por el hecho de que sus participantes son guapos) mientras que el numero de niños que lo ven es del 60\% (de los cuales el 32\% de ellos también lo ven porque los participantes son guapos). (Pregunta 3 )

Por otro lado, programación como la de Gran Hermano no tiene tanta importancia ni tanta repercusión entre los niños de 3 a 6 años. Se puede apreciar que tan solo el $22.8 \%$ de las niñas y el $32 \%$ de los niños ven este programa. Como dato significativo, cabe recalcar que este programa no tiene tanta aceptación entre los niños de estas edades, posiblemente porque los padres se niegan a que sus hijos vean este tipo de programas (el 80\% de las niñas y el $72 \%$ de los niños). (Pregunta 4)

La mayoría de los niños menores de 6 años están condicionados a la hora de ver la televisión, ya que hay un elevado porcentaje de niños / as que la ven con sus padres y admiten que muchas veces no ven los programas que ellos quieren (un $60 \%$ y un $80 \%$ respectivamente). (Preguntas 7,8 y 9) 
Y finalmente, es importante resaltar que actualmente los programas con más aceptación entre este tipo de público son las series de televisión (sobre todo entre las niñas, con un 45.7\%) y los dibujos animados (sobre todo entre los niños, con un 32\%), entre los que se encuentran Los Simpson y Las tres Mellizas como los más vistos y los que más gustan, y no por ser de carácter violento. (Preguntas 10,11,12,13 y 14)

GRÁFICOS MAS SIGNIFICATIVOS DE LOS NIÑOS ENTRE 3 Y 6 AÑOS

1), ¿Te gusta ver la televisión?

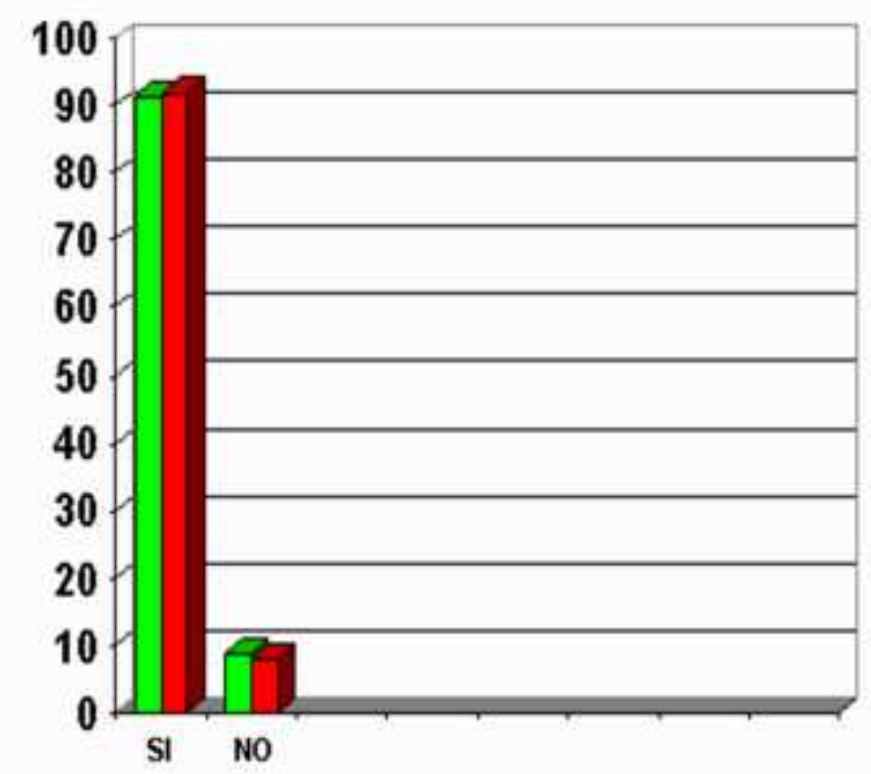

\section{$\square$ NIÑAS ㅁ№̃}


2), ¿Ves mucho la televisión la televisión?

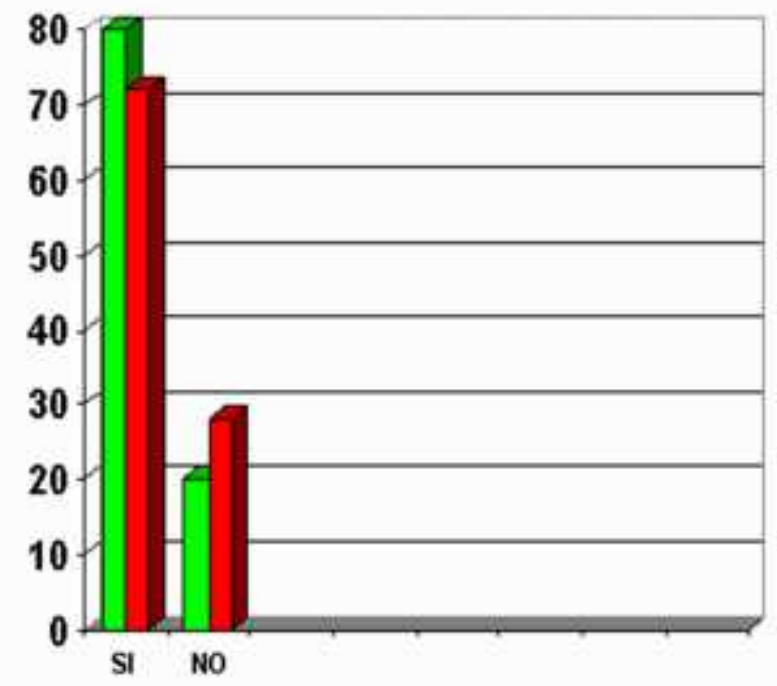

3), ¿Ves Operación Triunfo?

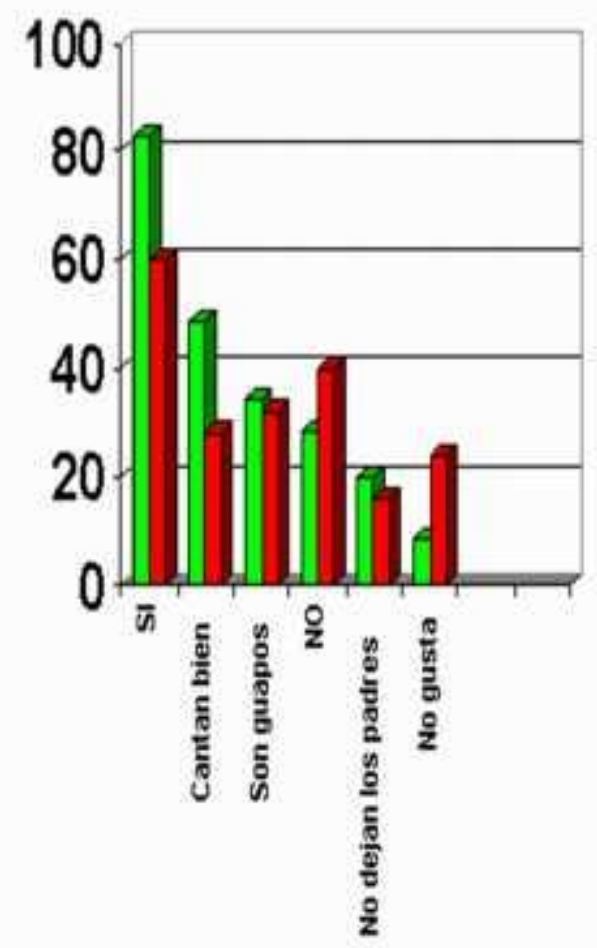


4), ¿Ves Gran Hermano?

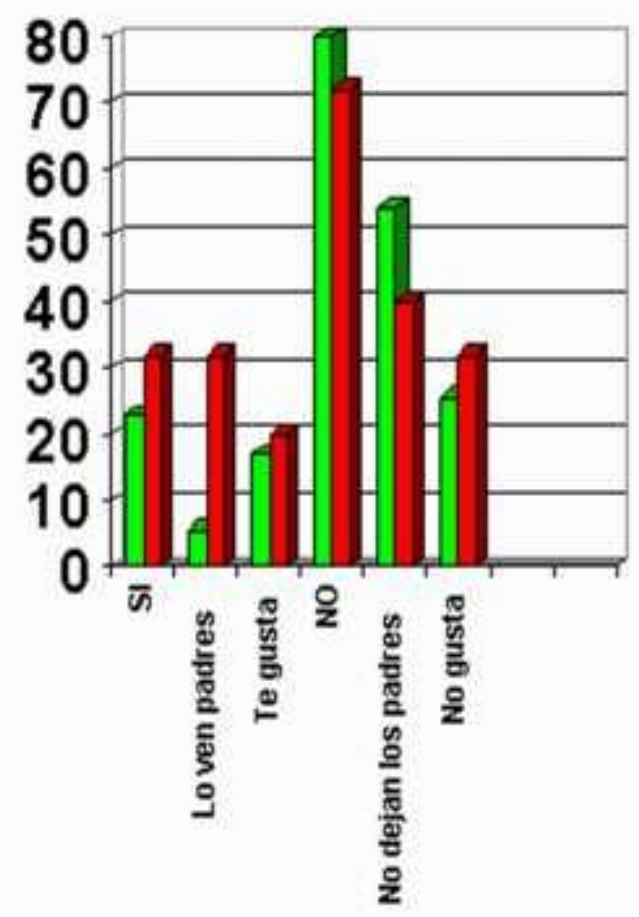

\section{$\square$ NIÑAS $\square$ NIÑOS}

5), ¿Te gustaría ir a Operación Triunfo?

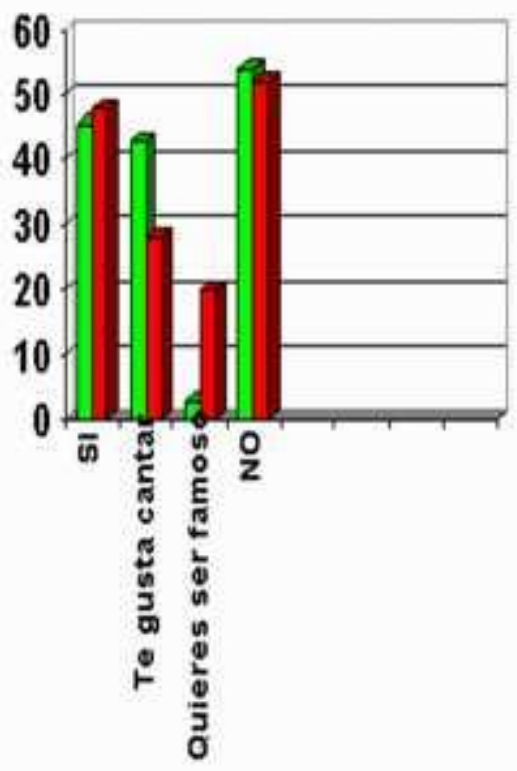


6), ¿Te gustaría ir a Gran Hermano?

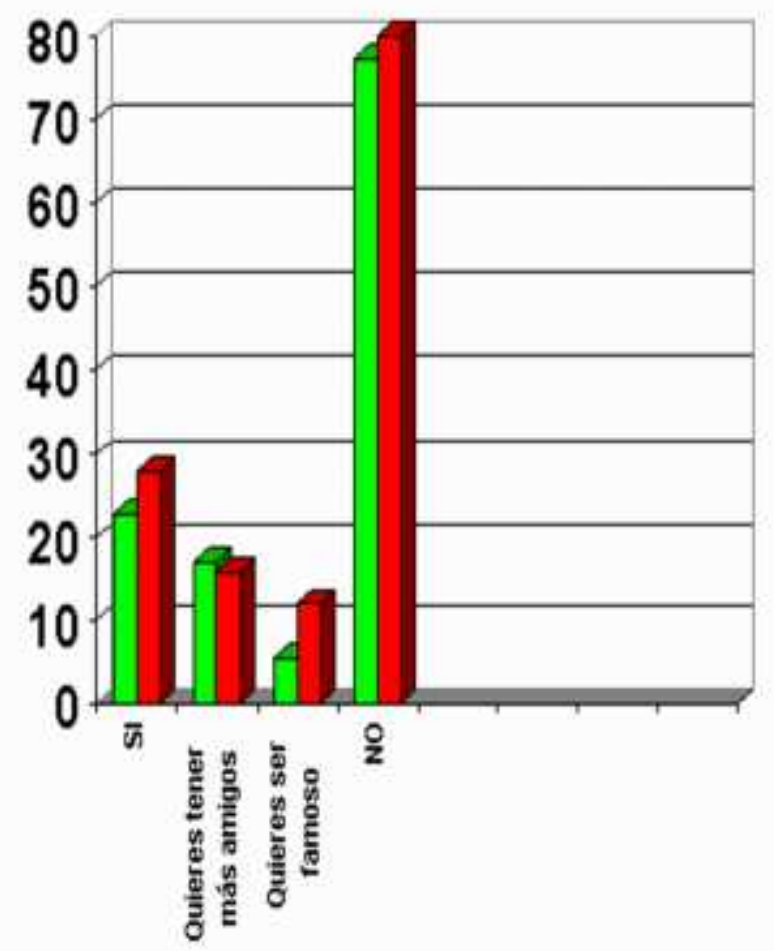

\section{口NIÑAS - NINOS}

7), ¿Ves la televisión con tus padres?

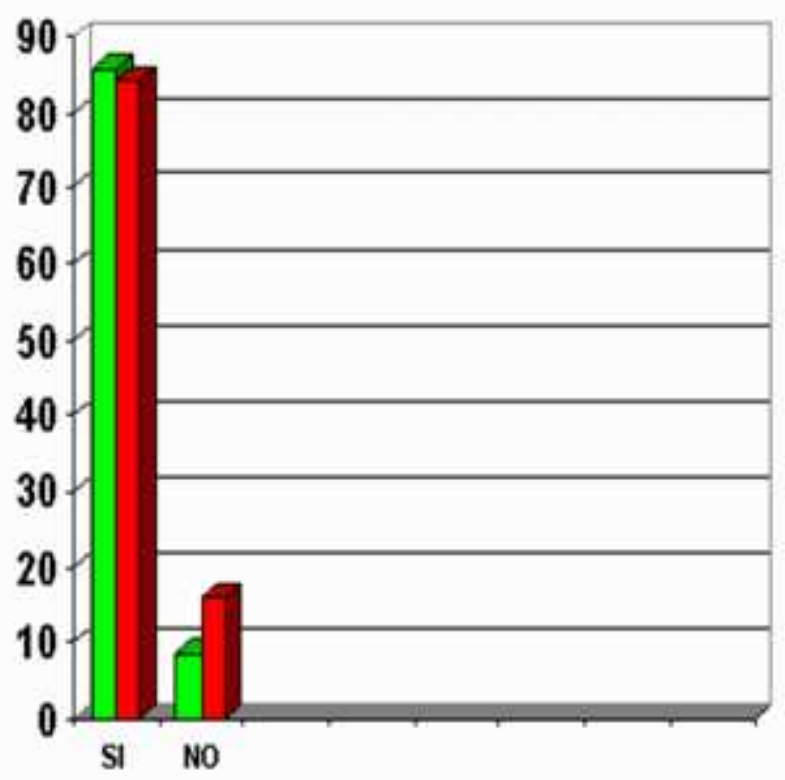


8), ¿Te quedas viendo la televisión hasta muy Tarde?

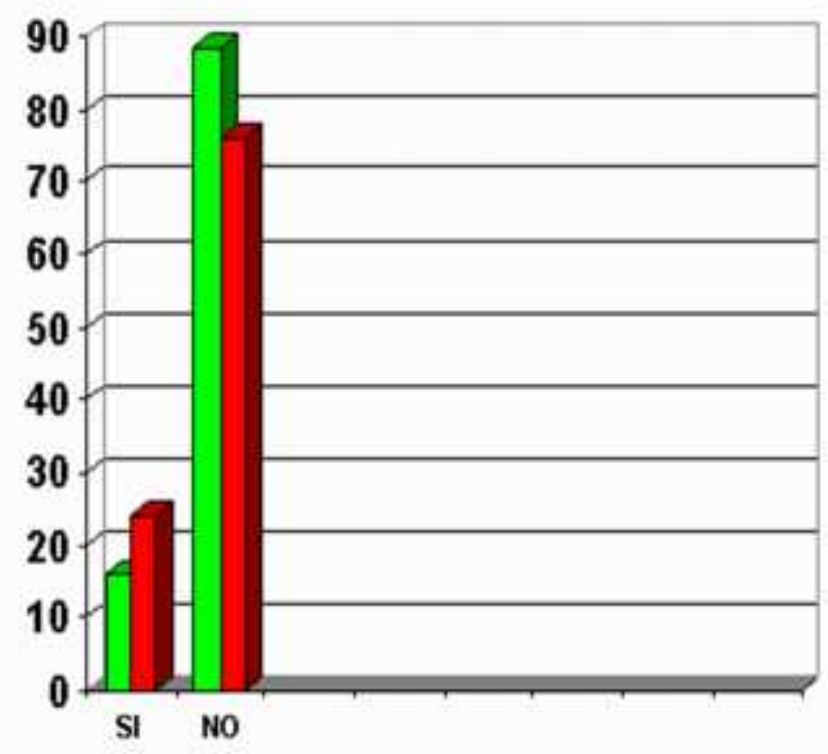

9), ¿Te dejan ver los programas que tú quieres?

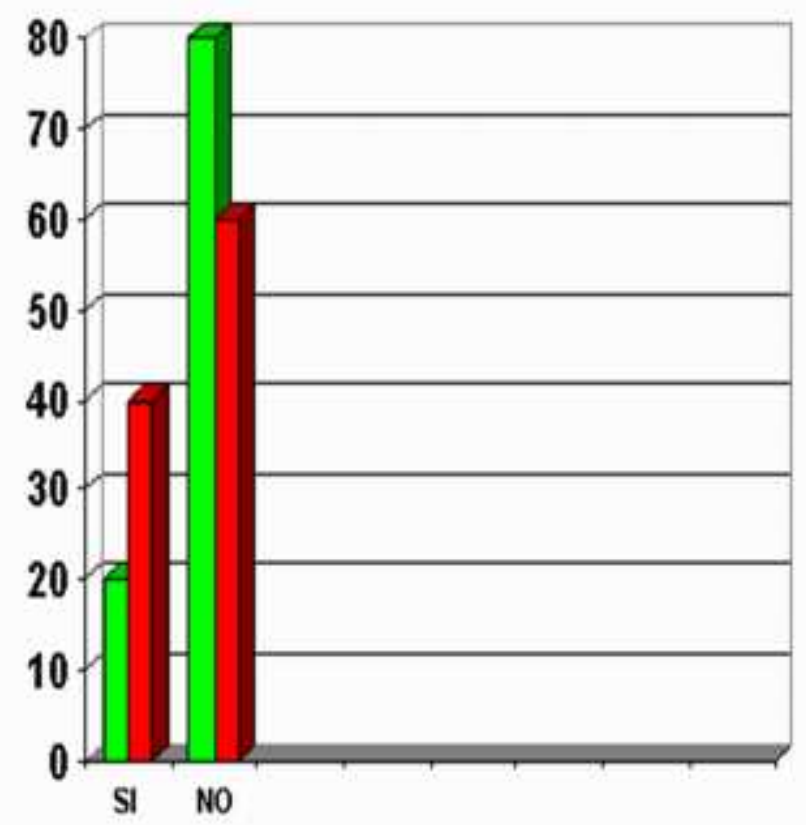


10.Si tus padres no están, ¿qué programas ves?

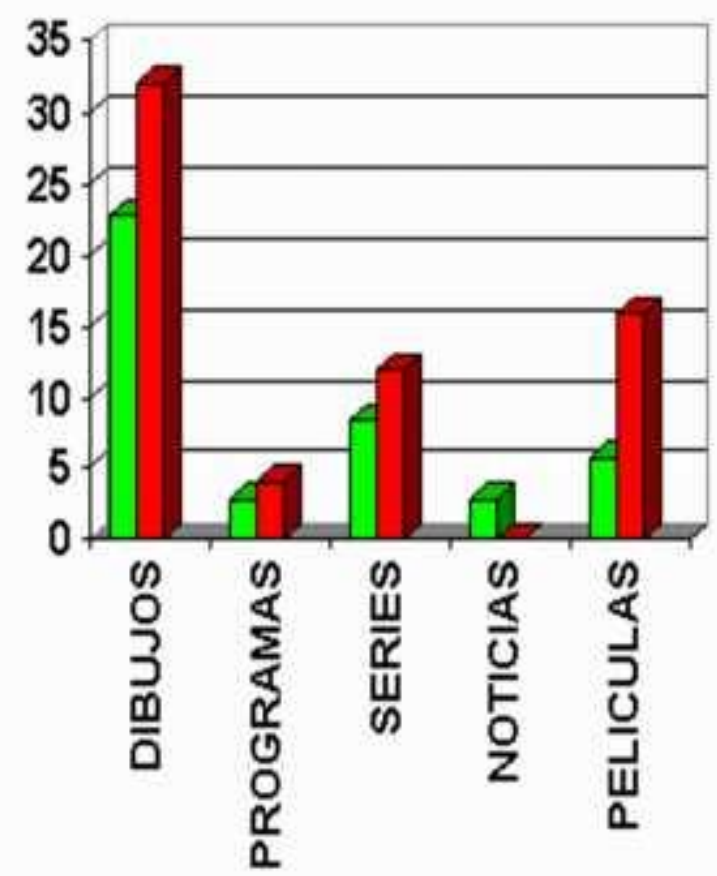

11.¿Qué dibujos te gustan ver?

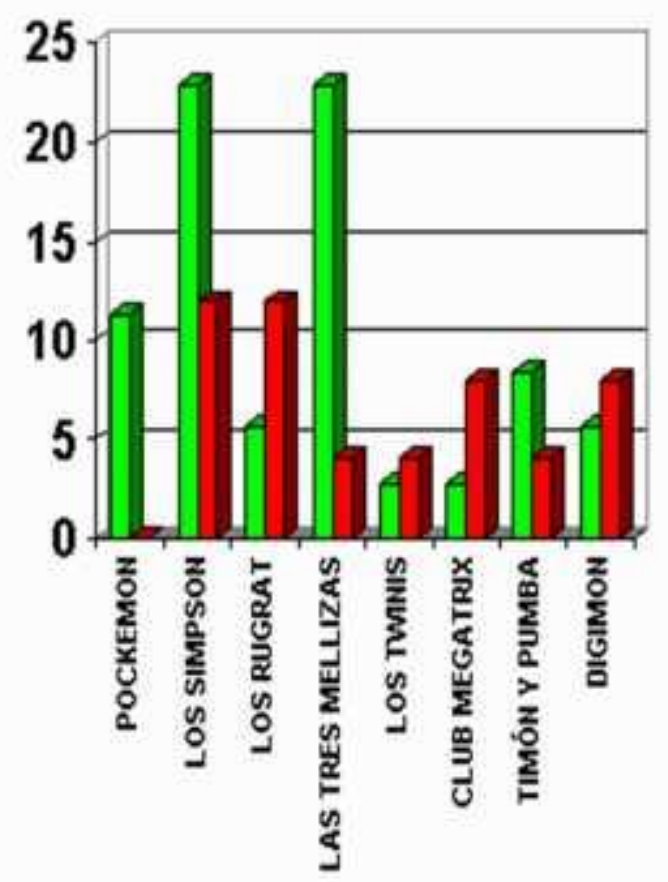


12.En esos dibujos, ¿los protagonistas se pelean?

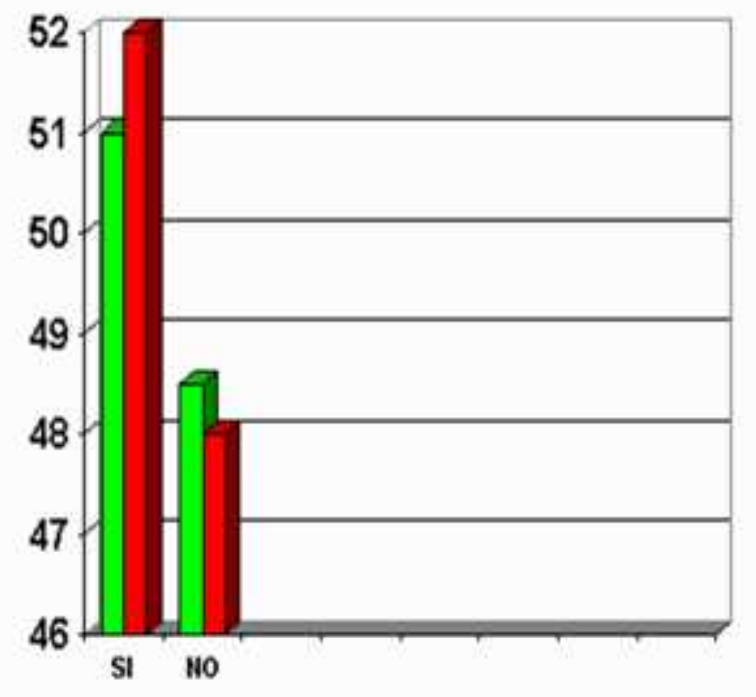

13. ¿Por qué te gusta verlos?

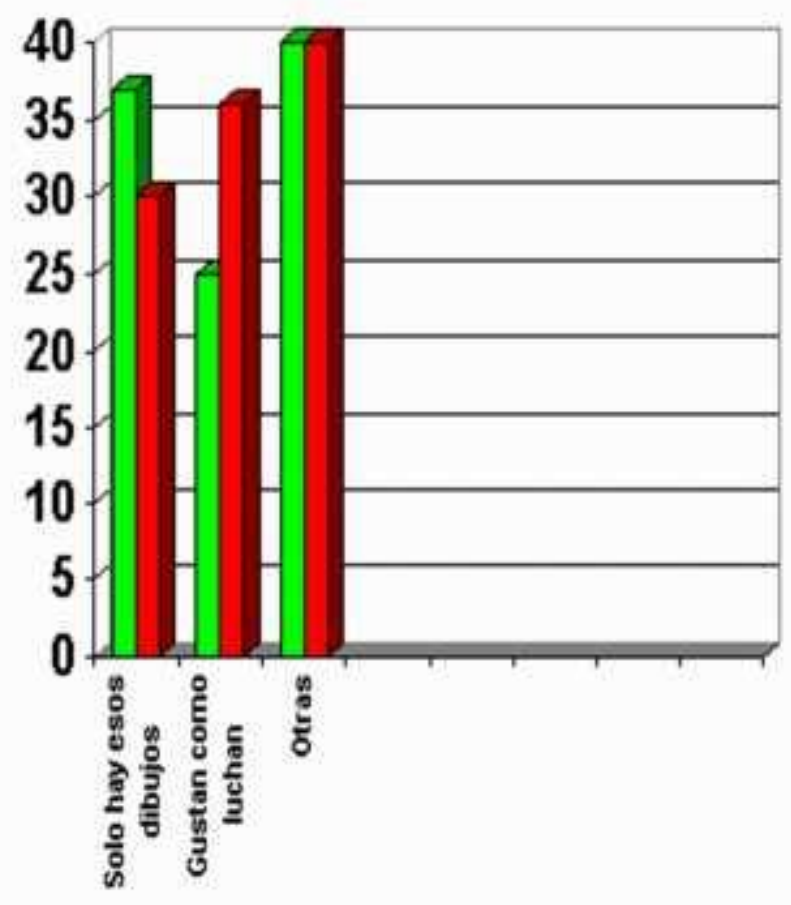


14.¿Qué otros programas, series, documentales te gustan?

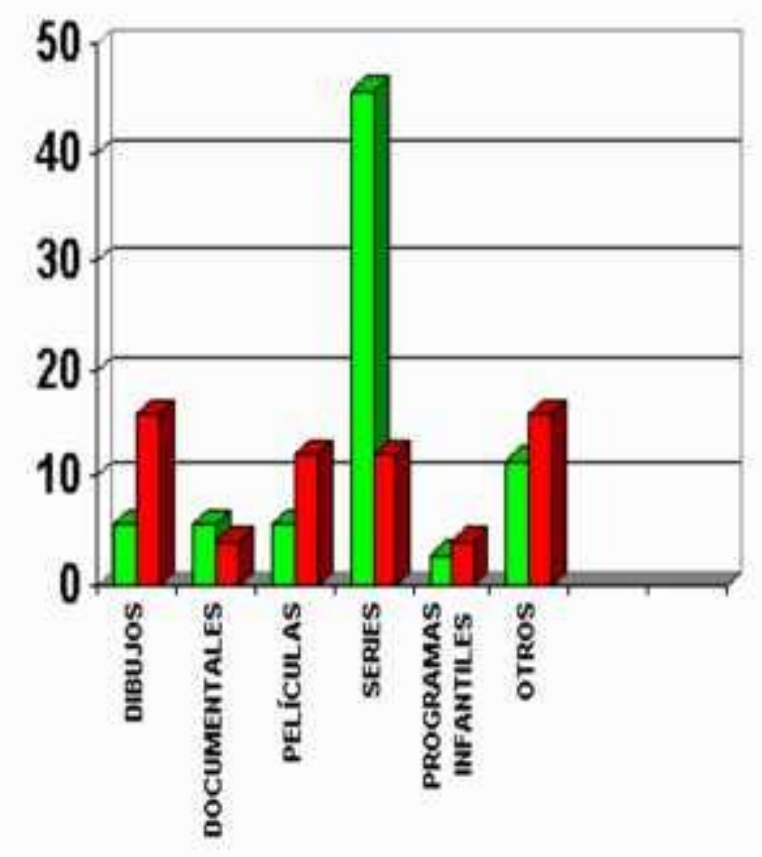

\section{VERIFICACIÓN DE HIPOTESIS}

\section{Los niños ven masivamente este tipo de programas de televisión.}

Está hipótesis queda rotundamente confirmada, teniendo como referencia la muestra de personas a las que hemos realizado las encuestas. De esta manera, podemos observar, que ver la TV es una de las actividades más realizada por los niños en general, anteponiéndola en muchos casos incluso a la de salir con los amigos o a la de hacer deporte.

Dentro de esta actividad, se puede afirmar que la "nueva" televisión se está convirtiendo en uno de los fenómenos más destacados en los últimos años, que está afectando no solo a los niños sino a toda nuestra sociedad. Programas como Operación Triunfo y Gran Hermano han dado la campanada y se han convertido en fenómenos televisivos imparables, que incluso actualmente están en expansión.

Se puede comprobar que Operación Triunfo cuenta con más adeptos entre los niños de 3 a 6 años (el 82.8\% de las niñas y el 60\% de los niños lo ven); mientras que Gran Hermano tiene más aceptación entre los chicos de 6 a 12 años (el 56.75\% de las chicas y el $47.82 \%$ de los chicos). Esto puede ser debido a que OT, al ser un espacio de música, los entretiene mejor ya que Gran Hermano seguramente es más complicado de entender para los más pequeños. De todos modos, podemos observar que los porcentajes entre un programa y otro se van igualando, a medida que la edad de los niños se incrementa. 


\section{Los niños se ven claramente influidos de manera negativa por este tipo de programación, sin embargo los adultos no son conscientes de ello.}

Esta hipótesis ni se puede confirmar ni se puede desmentir rotundamente. Los padres son los que realmente quieren y conocen a sus hijos, y por tanto no hay nadie mejor que ellos para saber lo que les conviene y lo que no. Se confirma la afirmación de que la televisión "mal utilizada" puede llegar a ser muy negativa para los niños, sobre todo con estas olas de violencia, sexo, ansias de poder... que están inundando nuestros televisores; esta es la parte de la hipótesis que realmente queda confirmada. Pero, por otro lado, se ha podido comprobar que la mayoría de los adultos si que son conscientes de que este tipo de programas influye de manera negativa en los niños. Incluso, en muchas ocasiones, son los propios padres los que ven estos programas con sus hijos; lo que refleja que aunque son conscientes de la negatividad de estos programas, son incapaces de ponerle remedio a este problema.

La televisión, como medio de comunicación que es, podría ser utilizado como un método bastante eficaz de aprendizaje, sobre todo en niños pequeños, si desapareciera la "programación basura".

Muchas de las encuestas y los estudios realizados, tanto en España como en el resto del mundo, reflejan que la televisión es uno de los métodos más eficaces de aprendizaje para los niños, sobre todo en los más pequeños. El hecho de que cuente con estímulos visuales y auditivos, hacen que sea un método muy atractivo para los niños, y estos centren su atención en lo que en ella se les está mostrando. La misión de la TV no es solo entretener y hacer que los niños pasen un rato divertido, si se les enseña a los niños desde pequeños a ver los programas adecuados, la televisión se puede convertir en un arma perfecta para transmitir cultura. Teniendo todo esto en cuenta, la hipótesis queda realmente afirmada.

\section{Los padres permiten que sus hijos vean cualquier tipo de programa, sin ningún} tipo de control ni medida.

Esta hipótesis, según las encuestas realizadas para este trabajo de investigación, es totalmente incierta. Según los datos obtenidos, la gran mayoría de los encuestados admite que ve la televisión con sus padres y que no siempre les dejan ver los programas que ellos quieren. Así mismo, queda reflejado en las encuestas y en los gráficos, que el $88.5 \%$ de las niñas y el $76 \%$ de los niños no se quedan viendo la TV hasta muy tarde, lo que quiere decir que gran parte de los padres actuales están preocupados por el contenido de ciertas programaciones y no permiten que sus hijos la vean a partir de ciertas horas ya que entienden que esto puede ser muy perjudicial para ellos.

Sin embargo, posiblemente, los padres no saben discernir entre los programas que 
pueden ver sus hijos y los que no porque ellos mismos ven a menudo canales “ telebasura "

\section{Esta "nueva" televisión es uno de los temas de más actualidad que existen hoy en día a pie de calle.}

Realmente, esta hipótesis es completamente cierta. Respuestas a las preguntas como quién ha ganado OT o a quién expulsaron ayer en Gran Hermano demuestran que están al día , y solo hay que salir a la calle para escucharlas. Este nuevo estilo de programas que se suceden en TV son temas de conversación de cualquier tertulia entre amigas, en los recreos, etc; Cualquier sitio es bueno para hablar de ellos.

De hecho, el $78.37 \%$ de las chicas y el $78.26 \%$ de los chicos de entre 6 y 12 años aunque no hemos incluido los resultado como hemos señalado- afirman que en la calle se habla muchísimo de este tipo de programas; incluso la mayoría de ellos llegan a afirmar que la gente sólo ve estos programas para poder estar al día de los comentarios que se hacen. Un total del $70.27 \%$ de las chicas y un $65.21 \%$ de los chicos llega a hacer esta afirmación. Estas cifras nos muestran la gran influencia que tiene la sociedad sobre nosotros.

\section{CONCLUSIONES}

Dentro de los medios de comunicación, la televisión es el más accesible para los niños, ya que está presente en la mayor parte de los hogares y no requiere de habilidades muy complejas para recibir la información, como sería, por ejemplo leer, en el caso de los libros y los periódicos. Es un medio de comunicación de masas, que por tener la facilidad de llegar a la mayoría de la población, se ha transformado en un arma de doble filo dada la calidad de programación que transmite sin considerar que, en la mayoría de los casos, sus espectadores son niños y jóvenes que no tienen un adulto que los oriente con relación a los temas que allí se desarrollan.

La importante y creciente cabida de la televisión en la sociedad, ha influido en la vida de todos sus miembros, sobre todo de los niños que son quienes pasan más horas frente al televisor y son más vulnerables ante sus efectos.

$\mathrm{Al}$ ver nuestra sociedad, podemos comprobar la importancia que tienen los medios de comunicación en nuestra vida, y a la vez, lo perjudicial, que, en ocasiones, pueden llegar a ser para los niños, ya que en algunos casos evidencian hechos de la vida sobre sexo, dogas, violencias, guerras, discriminaciones y alcohol, analizados sin ningún rigor científico ni ético. Hechos que perjudican a la mayoría porque los valores reales, estilo de vida y manera de vivir de cada uno está "manipulados "por modelos, valores y tipos de comportamientos, algunos de los cuales están bastante fuera del alcance de la mayoría de los hombres, pero otros pueden ser imitados y ejercer influencia directa sobre nuestro comportamiento y sobre todo sobre la conducta infantil

La televisión posee la peculiaridad de presentar estímulos visuales auditivos, los 
cuales son más efectivos que los visuales o auditivos por separado. Esta es una de las razones por la que se puede llegar aconvertir en un medio sumamente eficaz y más influyente que otros medios de comunicación social.

La televisión ejerce gran atractivo y ha desplazado en cuanto a preferencia a los demás medios. Sabido esto,la televisión pone en juego varias factores que son aprovechados por quienes la utilizan para la venta de productos, así como para la implantación de ideas políticas o sociales. El publico prefiere la televisión. No necesita de una determinada edad para ver la televisión.

Algunos medios de comunicación y algunos programas son utilizados con efectos poco éticos para lograr desarrollar el potencial cultural de nuestros pueblos. No se trata solo de comunicar, sino de controlar las reacciones del receptor e influenciarle en sus pensamientos e ideas.

Al decir que la TV tiene gran impacto en el desarrollo de los niños, no se refleja ninguna novedad, pero hay que admitir que las influencias no son todas negativas, también pueden llegar a ser positivas.

Con respecto a las influencias positivas se puede decir que son más débiles, pues los programas de este tipo son escasos y/o no están bien estructurados. En caso contrario. favorece al niño dándole una base más sólida en su aprendizaje, pero todo depende de cómo adquiera e interprete la información. También es importante destacar que la televisión permite, a través de este tipo de programas culturales, el conocimiento del mundo, de los diferentes países y sus culturas.

Uno de los grandes errores, es que la "masividad "de la televisión no ha sido bien aprovechada, debido, entre otras razones, a que toda la preocupación está puesta en sus aspectos negativos.

Por ultimo, es importante resaltar la enorme responsabilidad de los padres en la cantidad y calidad de televisión a la que están expuestos sus hijos, ya que los padres o adultos deberían poner ciertos límites y normas, edemas de promover una vida familiar con más comunicación e interacción entre sus miembros.

Los padres deberían utilizar todas las medidas que estén a su alcance para prevenir los efectos dañinos que la televisión puede tener en sus hijos. Aparte del contenido del programa de televisión, el tiempo que los niños dedican a esta actividad debería limitarse- actualmente están más tiempo viendo la televisión que en el colegioestimulándoles a que se dediquen más a otras actividades como son: la interacción familiar, el estudio y la lectura o el juego.

Si los padres tienen dificultades serias estableciendo controles y limites, o preocupación genuina en cuanto a la reacción del niño ante la televisión, deberían consultar con un especialista de niños que les ayudase y les aconsejase las pautas a seguir 


\section{BIBLIOGRAFÍA}

1. FEINBLOOM, Richards. (1989). Childrens andTelevision. Pediatrics. Vol. 57. $\mathrm{N}^{\mathrm{o}} 3$. March.

ROTHEMBER, Michael. (1975). EffectofTVViolenceonChildren and

Youth. Jama. Dec. 1975. Vol. 234. Nº 10.

(2002). Trepando hacia la Fama. Mujer 21. No 57, 82-87.

Azagra, P. (2002). La telerrealidad. Magazine Local (Cintruénigo). № 7, 12-14.

Drake, V. (2003). Los genios del escándalo. Revista semanal: Semana del 13 de Abril,18-26.

Marco, L.M. (2003). Basura televisión. Revista Dominical, 44-52.

Olza, I. (2003). Tele; Cuando decir basta. Ser Padres.

Silva, L. (2002). Los lectores deciden. OT: no es televisión de calidad. Revista El Semanal. N $\mathrm{N}^{\mathrm{T}} 785,8$.

Villacastín, R. (2002). Victima de la fama. Revista Mujer de hoy. $\mathrm{N}^{\circ}$ 183, 58. www.aacap.org/publications/apntesFam/violence.htm

www.bebesCR.com

www.binasss.sa.cr/adolescencia/television.htm

www.bvs.org.do/televisión.htm

www.iveargentina.org/index.htm

www.latera.com.mx/articu/articu0/castillo0.htm

www.mundolatino.org/saludmental/nintele.htm

www.parenting-ed.org/Spanish.htm

www.psych.med.umich.edu/web/aacap.htm

www.sunp.es/Document/comunica.htm

www.youthcarebarnes.com/pa/spg/btelevis.htm

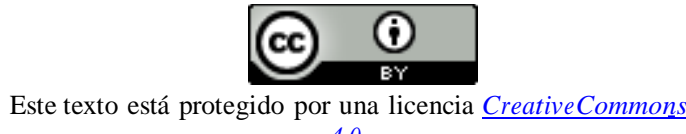

4.0.

Usted es libre para Compartir — copiar y redistribuir el material en cualquier medio o formato - y Adaptar el documen- to - remezclar, transformar y crear a partir del material- para cualquier propósito, incluso comercialmente, siempre que cumpla la condición de:

Atribución: Usted debe reconocer el crédito de una obra de manera adecuada, proporcionar un enlace a la licencia, e in- dicar si se han realizado cambios. Puede hacerlo en cualquier forma razonable, pero no de forma tal que sugiera que tie- ne el apoyo del licenciante o lo recibe por el uso que hace. 